\title{
Effect of Heat curing and E6-Glass Fibre Reinforcement Addition on Powder-based 3DP Cement Mortar
}

\author{
Pshtiwan Shakor $^{1 *}$, Shami Nejadi ${ }^{1}$ and Nadarajah Gowripalan ${ }^{1}$ \\ ${ }^{1}$ University of Technology Sydney, NSW, Australia \\ pshtiwan.shakoreuts.edu.au
}

\begin{abstract}
Powder-based 3D printing is one of the most promising techniques in additive manufacturing. The speed, resolution of the printed part and complicated geometries are important features in this technique and these features are usually not experienced in traditional construction techniques. This study aims to discuss the concept of using a custom-made powder (cement mortar) instead of a commercial (gypsum) powder in 3DP. Therefore, broad investigations are required to study and understand the details of the cement mortar 3D printed scaffold. This paper discovers the effect of heat-curing and addition of E6-glass fibres as reinforcement for the printed specimens. The results show that the mechanical properties of the cement mortar are improved through a heat-curing procedure. Addition of fibre reinforcement enhances powder flowability consistency and surface roughness throughout. Experiments are conducted on printed $50 \mathrm{~mm}$ cubic specimens, cured in an oven at different temperatures. The optimum heat-curing temperature is found to be $80^{\circ} \mathrm{C}$ to achieve the highest compressive strength in cement mortar specimens. Detailed 3D laser scanning of the printed cement mortar specimens is conducted. The $3 \mathrm{D}$ laser scanning results found rougher surface in cement mortar when it is not reinforced with glass fibre.
\end{abstract}

Keywords: powder-based 3DP; cement mortar; glass fibre; compressive strength; surface roughness.

\section{Introduction}

The increasing need for speed, quality and adapted design in the construction industry, pushes the additive manufacturing to another level of applications. The procedures for constructing structural members should be reconsidered and advanced for robust structures in the construction field [1].

Earlier studies have recognized three main techniques for the 3DP powder-bed process [2]: (i) selective cement activation; (ii) binder jetting; and (iii) selective paste intrusion. The selective binder activation process is usually known as powder-bed printing (binder/inkjet printing) [3,4] and it has been used in many applications for medical and biomedical purposes [5]. The key mechanism of the inkjet technique is to allow a drop of binder (water) to fall through a certain height on the bedded dry powder. The particular binder, that is used, has a major effect on the resolution, dimensional accuracy and surface finish of the printed parts [6,7]. The printer that is used in this study is a commercial printer, ProJet CJP 360, developed by Z-corp. However, all 
types of powder-based 3DP adopt a similar process. This printer has a maximum resolution of $(300 \times 450)$ Dots Per Inch (DPI) [8]. The resolution is highly dependant on changes of the powder particle sizes and binder content.

According to Aydın and Baradan [9], alkali activated slag mortar is more suitable to cure in autoclave when it has low $\mathrm{Na}_{2} \mathrm{O}$. Another study investigated the composition of inner C-S-H products and the hydration of the Portland cement mortar [10]. The mortar was cured at 4 hours or 28 days pre-cure at $20^{\circ} \mathrm{C}$ before heated at $90^{\circ} \mathrm{C}$ for approximate 12 hours and then stored in water at $20^{\circ} \mathrm{C}$. Their results showed that the $\mathrm{C}-\mathrm{S}-\mathrm{H}$ formed was denser and contained high sulfate at $90^{\circ} \mathrm{C}$ than the $\mathrm{C}-\mathrm{S}-\mathrm{H}$ formed at $20^{\circ} \mathrm{C}$. This has motivated significant research efforts on the application of different types of cement (for example, Calcium Aluminate cement and ordinary Portland cement) at different temperatures so as to find the optimum strength and optimum heat resistance of cementitious materials for 3DP. Research is also being conducted into the use of fibre reinforcement to enable the mortar to exhibit improved mechanical properties [11]. There are only a few studies particularly related to fibre reinforced gypsum and cement mortar for 3DP technology. Feng, Meng [12] used Fibre Reinforced Polymer (FRP) sheeting to reinforce the external surface of the printed gypsum prism by bonding it with resin. Christ, Schnabel [13] used chopped glass fibres with a length of 1-2 $\mathrm{mm}$ to prepare a gypsum reinforced scaffold which is very short filaments and is not convenient for reinforcement. Farina, Fabbrocino [14] also utilised the $3 \mathrm{D}$ printed rebars, made from polymeric and metallic fibres, embedded manually, in the cast-in-place mortar to compare reinforced specimens. Hence, the use of glass fibre as reinforcement in $3 \mathrm{D}$ printed components appears to be more feasible than using other types of fibre. In the present study, E6-Glass fibre with a length of $6 \mathrm{~mm}$ was used to print mortar specimens in the powder-based 3DP technique.

In addition, former studies on surface roughness and resolution are conducted on castin-place mortar prisms with different surface roughnesses 3DP polymer rebars [15]. Their study found that the smooth surface rebar could not be held by the mortar particles, whereas the rebar with a rough surface had improved performance. On the other hand, the surface roughness of the printed cementitious object has been found to be directly related to the powder particle sizes and the powder bed in the build-chamber [16]. Another factor which affects the resolution of the object is the flowability of the powder and the spreading of the powder particles on the build-chamber (build bin) $[16,17]$. Overall, there is not enough investigation on the surface roughness of cement mortar powder-based 3DP. In this paper, the surface roughness of glass fibre reinforced and unreinforced 3DP mortars are measured and compared.

The objective of this study is to experimentally examine the performance of 3DP mortar in the powder-based printing technique under heat cured conditions and in the presence/absence of fibres to reinforce the printed specimens. The compressive strengths of the 3DP mortar at various curing temperatures are evaluated until the optimised maximum compressive strength of the printed specimen was found. 


\section{Materials}

\subsection{Material properties}

The modified cement powder was formulated based on the commercial powder, ZP 151, whose major chemical composition was calcium sulphate hemihydrate $\left(\mathrm{CaSO}_{4} \cdot 0.5 \mathrm{H}_{2} \mathrm{O}\right)(80-90 \%)$ produced by the 3DSystems [18]. The particle sizes were produced to be as close as possible to the commercial material. For further detail and relationship between particle sizes refer to earlier studies [3,4].

The modified mix that was used for powder-based 3DP in this research contained $67.8 \%$ of Calcium Aluminate Cement (CAC) using a ranging sieve of $75-150 \mu \mathrm{m}$, $32.2 \%$ of Ordinary Portland Cement (OPC) and 5\% of fine sand as a percentage of total weight. The selection of materials was based on the particle size flowability and quick setting properties of the materials. For example, CAC had good resistance for abrasion, acid resistance and quick setting. In the 1950s, the CAC mortar was used as lining for the Portland concrete pipes in Kuala Lumpur. It has also been used in many other countries such as Egypt and South Africa [19].

The physical properties of the E6-glass fibres used in printing fabrication are shown in Table 1.

Table 1. Physical properties of chopped E6-glass fibre filament

\begin{tabular}{lllllll}
\hline Fibre type & Length & $\begin{array}{l}\text { Filament } \\
\text { diameter } \\
(\boldsymbol{\mu m})\end{array}$ & $\begin{array}{l}\text { Specific } \\
\text { gravity } \\
\left(\mathbf{g} / \mathbf{c m}^{\mathbf{3}}\right)\end{array}$ & $\begin{array}{l}\text { Tensile } \\
\text { strength } \\
(\mathbf{M P a})\end{array}$ & $\begin{array}{l}\text { Tensile } \\
\text { modulus } \\
(\mathbf{G P a})\end{array}$ & $\begin{array}{l}\text { Expansion } \\
\text { coefficient }\left(\mathbf{1 0}^{-}\right.\end{array}$ \\
$\begin{array}{l}\left.\mathbf{6}^{-\mathbf{1}}\right) \\
\text { E6-Glass fibre } \\
\text { (Trojan) }\end{array}$ & $6 \pm 1$ & $13 \pm 1$ & $2.62-2.63$ & $2500-2700$ & 81 & 6 \\
\hline
\end{tabular}

\subsection{Powder mixing}

After selecting the type of materials and their mix proportions, the materials were blended homogeneously. The modified powder was thoroughly mixed using a Hobart mixer at a speed of $1450 \mathrm{rpm}$.

The homogeneity and consistency of the powder were significant factors that must be controlled when in pursuit of superior surface roughness and strength results. Hence, the speed of the mixer and the blending time were found to be the main contributors to the homogeneity of the powder and for production efficiency of 3DP objects [20]. 


\section{Methods}

\subsection{Specimen preparation}

Specimens with dimensions of $50 \times 50 \times 50 \mathrm{~mm}$ were tested for compressive strength. As shown in Table 2, three specimens for each group were prepared for each test, based on 6 different curing conditions.

Table 2. Detailed number and dimension of specimens

\begin{tabular}{llll}
\hline Specimen description & CAD dimensions $(\mathbf{m m})$ & Number of specimens & Printed plane \\
\hline Plain cube & $50 \times 50 \times 50$ & 18 & $\mathrm{XY}$ \\
\hline Fibre-reinforced cube & $50 \times 50 \times 50$ & 18 & $\mathrm{XY}$ \\
\hline
\end{tabular}

Fig. 1 provides all details of the planes (XY, XZ, YZ) and the applied loads on the $\mathrm{XY}$ plane. Fig. 1 also displays the green part for a 3DP mortar cube ( the green part is defined as the fabricated part after printing and removal from the build-chamber of the printer, prior to commencing any post-processing procedure such as curing).

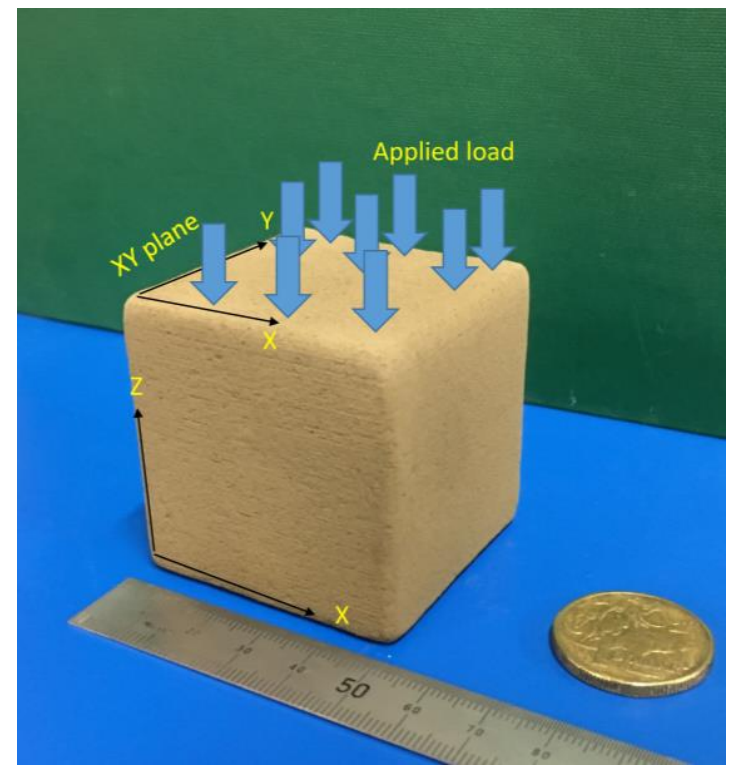

Fig. 1. The green part of the $3 \mathrm{DP}$ cement mortar cube $50 \times 50 \times 50 \mathrm{~mm}$ and illustration of a cube tested on the plane (XY)

\subsection{Post-processing of specimen}

After a specimen was printed, it was left in the printer for approximately 2 hours before curing. The post-processing consists of (a) curing one group of specimens for 28days in tap water; (b) curing another group of specimens in the oven for 3-hours, storing in water for 28 days and then drying in the oven for 3-hours. This same basic 
post-processing sequence was used for all specimens, but at various temperatures. Specimens were cured under the following different conditions: cured in tap water only, (cured for 3-hours at $40^{\circ} \mathrm{C}, 28$-days water, 3-hours at $40^{\circ} \mathrm{C}$ ), (cured for 3-hours at $60^{\circ} \mathrm{C}, 28$-days water, 3-hours at $60^{\circ} \mathrm{C}$ ), (cured for 3-hours at $80^{\circ} \mathrm{C}, 28$-days water, 3 -hours at $80^{\circ} \mathrm{C}$ ), (cured 3 -hours at $90^{\circ} \mathrm{C}, 28$-days water, 3-hours at $90^{\circ} \mathrm{C}$ ) and (cured for 3-hours at $100^{\circ} \mathrm{C}, 28$-days water, 3-hours at $100^{\circ} \mathrm{C}$ ).

\subsection{Compressive strength test}

Cubic specimens were subjected to the compressive strength test. The compressive strength test was performed for the 3DP specimens according to the ASTM standard [21]. A total of 36 specimens were printed and tested, including 3 specimens for each curing process and 3 specimens with the presence/absence of glass fibre. The rate of loading in the compressive strength test was fixed at $0.833 \mathrm{kN} / \mathrm{s}$.

\section{$4 \quad$ Results and discussion}

\subsection{Compressive strength}

Influence of the strength of material is significant to measure the ability of materials behaviour to resist the applied load.

Fig. 2 presents the compression strength of the printed mortar using 1\% E6-glass fibre as reinforcement and curing at different temperatures. Specimens curing at $80^{\circ} \mathrm{C}$ attained the optimum compressive strength for the printed mortar. The compressive strength of mortar with $1 \%$ glass fibre was recorded as $37.88 \mathrm{MPa}$, which is quite suitable for the construction industry and precast construction applications. 


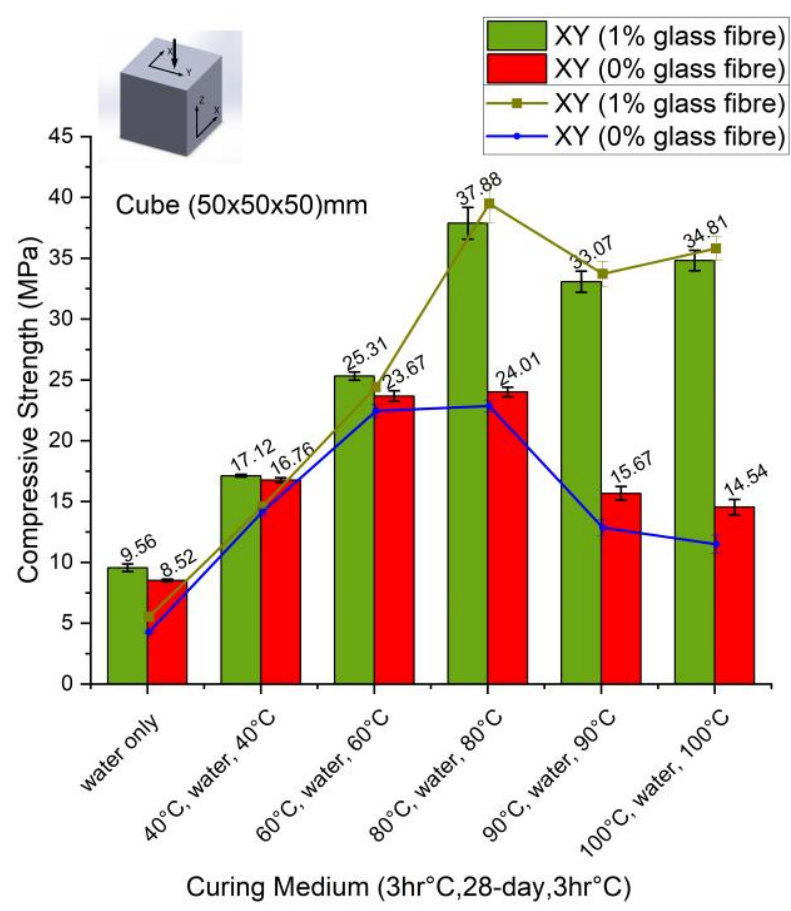

Fig. 2. Compressive strength of mortar specimen $50 \times 50 \times 50 \mathrm{~mm}$ with/without glass fibre using different curing media

The increased strength in the cement mortar proportional to the increase in temperatures was due to the greater reaction level of the cement mortar at the raised temperatures at early ages. Curing in an oven accelerated the reaction of the cementitious process. Fast hydration and a high early compressive strength were observed as the temperature was increased [22].

These results are positive for the construction industry and precast construction applications. This study used optimal saturation levels that are detailed in the earlier studies $[3,4]$ to show the strongest plane and direction in addition to the optimised elevated temperature, which is the optimum to attain the highest compressive strength. For long term durability and checking the quality of the materials, it is necessary to conduct further investigations, such as monitoring the surface quality of the printed structure in harsh environments and checking the serviceability limit state of the printed structural members.

\subsection{Surface roughness}

Abbreviation "Ra" is a value used to describe the surface textures of the materials. $\mathrm{Ra}$ expresses as arithmetic mean deviation of the roughness profile which is determined by height deviation of the surface from a mean line within the evaluation length. A substantial change has been observed when glass fibre was added to the cement mortar. 
Adding fibres into printed specimens significantly affect the porosity and surface roughness. The porosity of the composite materials has an impact on the mechanical properties of the specimens. The porosity of the printed scaffold reduced by fibre reinforcement due to the well-distributed fibres on the powder-bed chamber before the printing process. Fig. 3 shows the surface roughness profile of printed specimens in the presence and absence of glass fibre. That figure clearly shows a reduction in the roughness of the surface morphology of the cubic specimen. Overall, the surface roughness of the cubic cement mortar specimen with $1 \%$ glass fibre is $18.57 \pm 1.35 \mu \mathrm{m}$ and that of the specimen without glass fibre is $22.31 \pm 3.72 \mu \mathrm{m}$.

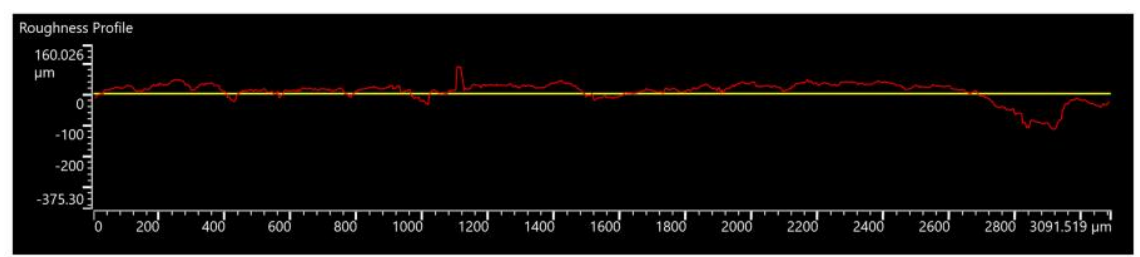

Roughness Profile of Printed Cement Mortar Cube

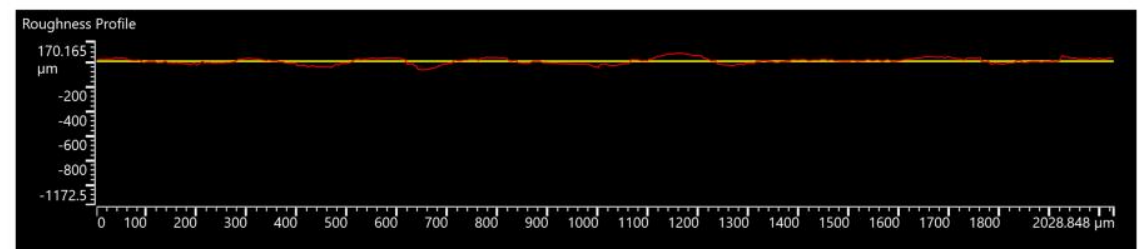

Roughness Profile of Printed Cement Mortar Cube with $1 \%$ glass fibre

Fig. 3. Comparison of printed cement mortar specimens in the presence/absence of glass fibre

Fig. 4 shows the 3D laser scanner capture of the fibre filaments in the printed specimens. It clearly shows the approximate length at the edge of the specimen and the diameter of the specimen. The approximate length of the filaments extending beyond the edge is approximately $400 \mu \mathrm{m}$, with the rest of fibre's length inside the printed mortar. The diameter is approximately $13.49 \mu \mathrm{m}$. Consequently, this is proof that the filament is not damaged during printing and solidifying. 

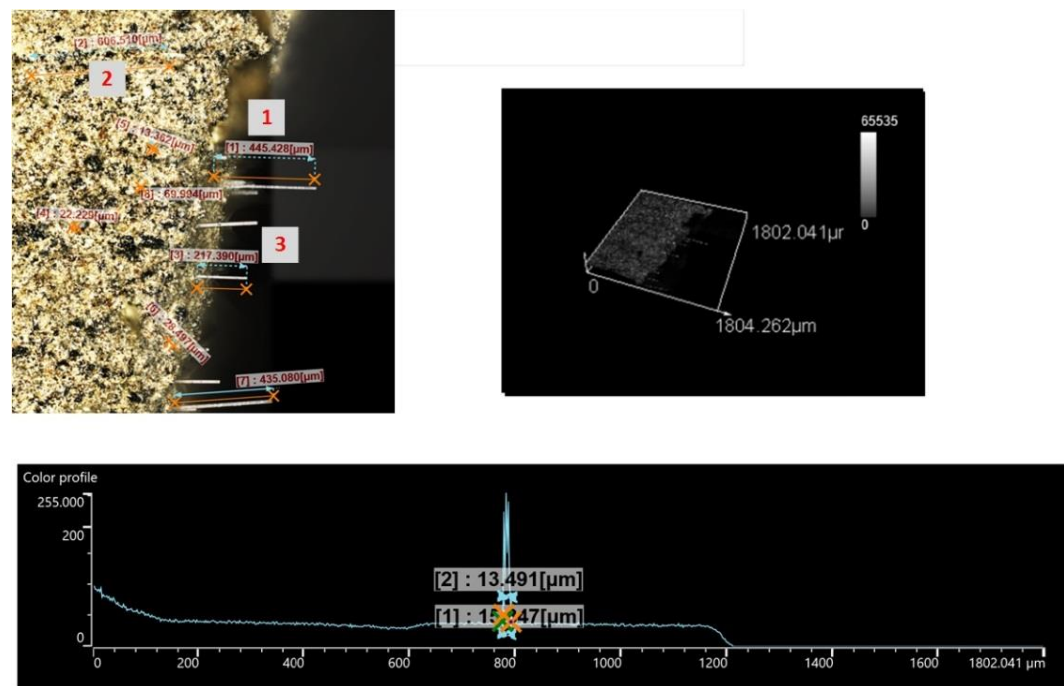

Fig. 4. Filament diameter and length of the fibre in the printed specimens. In the top left image (1) fibre filament extends $445 \mu \mathrm{m}$ beyond the edge of the specimen; (2) fibre filament length of $606 \mu \mathrm{m}$ in the specimen, (3) fibre filament length of $217 \mu \mathrm{m}$ beyond the edge of the specimen.

\section{Conclusions}

From this study the following conclusions can be achieved:

- 3DP technology is emerging as an advanced technique to construct highly detailed complicated geometries, which are conventionally difficult to construct

- The maximum compressive strength was recorded at $80^{\circ} \mathrm{C}$ in the presence/absence of $1 \%$ E6-glass fibres

- The surface roughness measurements showed that cement mortar specimen with fibre had an even and uniform surface compared to specimens without fibres

Further research on powder-based 3DP is required, specifically on post-processing, curing, and infiltration, early age shrinkage of the printed specimens such as autogenous shrinkage, chemical shrinkage and plastic shrinkage. Ideally, that research should focus on broader applications for construction purposes, such as an investigation of larger-scale 3DP in real-life. 


\section{References}

1. Shakor, P., et al., Review of Emerging Additive Manufacturing Technologies in 3D Printing of Cementitious Materials in the Construction Industry. Frontiers in Built Environment, 2019. 4(85).

2. Lowke, D., et al., Particle-bed $3 D$ printing in concrete construction - Possibilities and challenges. Cement and Concrete Research, 2018.

3. Shakor, P., et al., Modified $3 D$ printed powder to cement-based material and mechanical properties of cement scaffold used in $3 D$ printing. Construction and Building Materials, 2017. 138: p. 398-409.

4. Shakor, P., et al., Mechanical Properties of Cement-Based Materials and Effect of Elevated Temperature on Three-Dimensional (3-D) Printed Mortar Specimens in Inkjet 3-D Printing. ACI Materials Journal, 2019. 116(2): p. 55-67.

5. Chua, C.K. and K.F. Leong, 3D Printing And Additive Manufacturing: Principles And Applications (With Companion Media Pack) Of Rapid Prototyping. 2014, Singapore, Singapore World Scientific Publishing Co Inc.

6. Jooho, M., et al., Ink-Jet Printing of Binders for Ceramic Components. Journal of the American Ceramic Society, 2002. 85(4): p. 755.

7. Yang, H., et al., Performance evaluation of ProJet multi-material jetting $3 D$ printer. Virtual and Physical Prototyping, 2017. 12(1): p. 95-103.

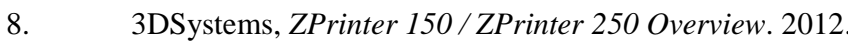

9. Aydın, S. and B. Baradan, Mechanical and microstructural properties of heat cured alkali-activated slag mortars. Materials \& Design, 2012. 35: p. 374-383.

10. Famy, C., et al., Effects of an early or a late heat treatment on the microstructure and composition of inner CSH products of Portland cement mortars. Cement and Concrete Research, 2002. 32(2): p. 269-278.

11. Li, V.C. and M. Maalej, Toughening in cement based composites. Part II: Fiber reinforced cementitious composites. Cement and Concrete Composites, 1996. 18(4): p. 239-249.

12. Feng, P., X. Meng, and H. Zhang, Mechanical behavior of FRP sheets reinforced $3 D$ elements printed with cementitious materials. Composite Structures, 2015. 134: p. 331-342.

13. Christ, S., et al., Fiber reinforcement during 3D printing. Materials Letters, 2015. 139: p. 165-168.

14. Farina, I., et al., Surface roughness effects on the reinforcement of cement mortars through $3 D$ printed metallic fibers. Composites Part B: Engineering, 2016. 99: p. 305-311.

15. Farina, I., et al., On the reinforcement of cement mortars through $3 D$ printed polymeric and metallic fibers. Composites Part B: Engineering, 2016. 90: p. 76-85.

16. Zhou, Z., et al., Printability of calcium phosphate: calcium sulfate powders for the application of tissue engineered bone scaffolds using the 3D printing technique. Mater Sci Eng C Mater Biol Appl, 2014. 38: p. 1-10.

17. Shanjani, Y. and E. Toyserkani. Material spreading and compaction in powder-based solid freeform fabrication methods: mathematical modeling. in 19th Annual International Solid Freeform Fabrication Symposium, SFF. 2008. 
18. $\quad 3 D S y s t e m s, ~ Z P 151$ Powder Safety Data Sheet. 2013.

19. Scrivener, K.L. and A. Capmas, 13 - Calcium Aluminate Cements, in Lea's Chemistry of Cement and Concrete (Fourth Edition), P.C. Hewlett, Editor. 1998, ButterworthHeinemann: Oxford. p. 713-782.

20. Hill, J., J. Orr, and N. Dunne, In vitro study investigating the mechanical properties of acrylic bone cement containing calcium carbonate nanoparticles. Journal of Materials Science: Materials in Medicine, 2008. 19(11): p. 3327-3333.

21. ASTMC39, 39, Standard test method for compressive strength of cylindrical concrete specimens. ASTM International, 2001.

22. Lothenbach, B., et al., Effect of temperature on the pore solution, microstructure and hydration products of Portland cement pastes. Cement and Concrete Research, 2007. 37(4): p. 483-491. 